\title{
O perfil ideal do juiz para as decisões em saúde
}

Ideal judges profile to health decisions

Maria Célia Delduque

Advogada, Doutora em Saúde Pública, Pesquisadora, Coordenadora do Programa de Direito Sanitário da Fundação Oswaldo Cruz, Brasília, Brasil

Resumo: O artigo trata do tema das decisões judiciais em saúde. Parte do princípio de como prosperou o fenômeno da judicialização no Brasil para compreender a lógica jurídico-formal de formação do convencimento do juiz para por fim demonstrar os modelos de juízes que a doutrina contempla, discutindo-se o perfil ideal para julgar as questões sobre saúde.

Descritores: Decisões judiciais; Direito Sanitário; saúde.

Abstract: This article is about court decisions in health cases. It's based on the growing judicialization phenomena in Brazil and tries to understand the legal-formal logic related to the construction of judge conviction. At last it will enumerate the judges models considered by the doctrine in order to discuss which is the ideal profile to judge health cases.

Keywords: Court decisions; Health Law; health.

$\mathrm{Na}$ contemporaneidade tem-se observado uma busca incessante do Poder Judiciário para a realização de direitos sociais garantidos no texto constitucional e nas leis federais. Não se trata de um fenômeno genuinamente brasileiro ou que se limite às questões de ordem sanitária, mas um fenômeno mundial que abarca todos os direitos sociais. O fato é que a judicialização da política pública de saúde é um fenômeno na paisagem jurídica brasileira. 
O problema denominado judicialização do direito à saúde ganhou importância teórica e prática no Brasil e disso resultou o envolvimento não apenas do Poder Judiciário, mas também dos gestores públicos, da sociedade civil e dos profissionais da área da saúde. Gerou um forte tensionamento entre dois pólos: de um lado, os formuladores e executores da política pública sanitária, responsáveis pela prestação de serviços de saúde e a execução financeiro-orçamentária do setor, implicando o quanto disponibilizar e a quem atender como típica opção política, seguindo critérios de justiça distributiva. De outro lado, o Poder Judiciário, vocacionado a concretizar a microjustiça (justiça do caso concreto) sem condições de examinar as consequências globais da destinação de recursos públicos em benefício da parte, com invariável prejuízo para o todo (Amaral, 2001).

A judicialização, nas palavras de Barroso (2009, p.2), "significa que algumas questões de larga repercussão política e social estão sendo decididas por órgãos do Poder Judiciário, e não pelas instâncias políticas tradicionais: o Congresso Nacional e o Poder Executivo". Isso significa que a judicialização é a transferência do poder para juízes e tribunais o que vai implicar "alterações significativas na linguagem, na argumentação e, especialmente, no modo de participação da sociedade" (Barroso, 2009, p. 2).

A judicialização decorre, segundo Barroso (2009), de três principais causas: a primeira delas é a própria redemocratização do país, que recuperou as garantias da magistratura e alçou o Judiciário a um verdadeiro poder político. $\mathrm{O}$ ambiente democrático permitiu que um maior número de pessoas pudesse exercer a cidadania buscando o Judiciário para a proteção de seus interesses. Além disso, houve a expansão do Ministério Público para outras áreas fora do estritamente penal, bem como a presença crescente da Defensoria Pública em várias partes do Brasil.

Os direitos de prestação positiva pelo Estado assegurados na Constituição da República são uma segunda causa da crescente judicialização, porque uma vez que um direito é disciplinado em uma norma constitucional, ele se transforma potencialmente em uma pretensão jurídica, que pode ser formulada sob a forma de ação judicial. Por exemplo: a Constituição garante a saúde como direito de todos. É possível judicializar a exigência desse direito, levando ao Judiciário o 
debate sobre ações concretas nas quais esse direito possa ser ameaçado ou sobre as políticas públicas que objetivam dar-lhe materialidade.

A terceira e última causa para a judicialização, segundo Barroso, é o sistema brasileiro de controle de constitucionalidade. O Brasil adota dois sistemas de controle de constitucionalidade, um incidental e difuso e outro concentrado ou por ação direta. Isso significa que se pode questionar a constitucionalidade de qualquer lei perante qualquer juiz ou tribunal em um caso concreto ou por ação direta perante o Supremo Tribunal Federal. Nesse último caso, apenas algumas entidades públicas e privadas, previstas no art. 103 da Constituição da República, têm a prerrogativa da ação.

Appio (2007) revela seu ceticismo sobre a transferência ao Poder Judiciário das funções dos demais Poderes da República. Acredita o autor que o Judiciário não tem condições de indicar fontes de recursos para dar cumprimento às suas decisões e que a imposição coercitiva de políticas públicas pelos juízes significaria uma "aristocracia judiciária" (Appio, 2007, p. 156), totalmente incompatível com o sistema representativo.

Loewenstein afirma que:

La intervención de los tribunales puede conducir a borrar las fronteras entre la administración de justicia y la política. Los detentadores del poder, politicamente responsables - gobierno e parlamento, están expuestos a la tentación de llevar ante el tribunal un conflicto político. Los jueces, por su parte, están obligados a sustituir las decisiones de los responsables detentadores del poder por sus juicios políticos, camuflados en forma de sentencia judicial. Instalar un tribunal como árbitro supremo del proceso del poder - y este es el núcleo de la judicialización de la política -, transformaria, en último término, el sistema gubernamental en un domínio de los jueces o en una judiciocracia. (Loewenstein, 1970, p. 325) ${ }^{1}$

Campilongo (2000; 2002), para quem a democracia constitucional pressupõe a separação entre os sistemas político e jurídico, cada qual perseguindo a sua função específica, entende que a judicialização da política e a

\footnotetext{
1 "As intervenções dos tribunais podem conduzir à quebra das fronteiras entre a administração de justiça e a política. Os detentores do poder, politicamente responsáveis - governo e parlamento, estão expostos à tentação de levar aos tribunais um conflito político. Os juízes, por sua parte, estão obrigados a substituir as decisões dos responsáveis pelo poder por seus juízos políticos, camuflados de sentença judicial. Instalar um tribunal como árbitro supremo do processo de poder - e este é o núcleo da judicialização da política - transformaria, ao final, o sistema governamental em um domínio dos juízes, ou seja, uma judiciocracia.". [Tradução livre da autora].
} 
sobreposição das decisões judiciais e do arcabouço normativo às opções políticas representam uma ameaça à democracia e complexidade interna desses sistemas.

Grupo distinto reconhece legitimidade ao controle das políticas públicas pelo Poder Judiciário. Cappeletti (1999) apresenta argumentos que sustentam a legitimidade democrática na atividade judicial, e que o controle dos atos políticos releva-se fundamental para um verdadeiro equilíbrio entre os poderes no chamado estado de bem-estar social, onde se agigantam os Poderes Legislativos e Executivos do Estado e o número de normas jurídicas que regulamentam a vida social, política e econômica.

A referência do sistema jurídico é sempre normativa. A produção do Direito dá-se por meio do próprio Direito. Então, operacionalmente, o direito distingue fatos e normas. É com base no seu programa condicional que o sistema jurídico decide quem tem razão à luz do próprio Direito ou, melhor dito, a validade de uma norma é sempre uma norma e não um fato. (Luhmann, 2004, p. 103).

Sua função de estabilizar as expectativas normativas implica que o direito pode intervir nos demais subsistemas sociais. Mas o uso político do direito altera sua estrutura interna (Teubner, apud Villas Bôas 2001).

Mas, se o sistema jurídico funciona com seu código e programas próprios, fica evidente que na sua inter-relação com o sistema político, no que se refere à saúde, deverá considerar as normas e regramentos definidores da política pública de saúde, posto que é no arcabouço infralegal que se definem as metas e resultados a serem alcançados pela política pública. A prática demonstra, no entanto, que as decisões judiciais fundamentam-se apenas no texto constitucional $^{2}$.

O fato é que, ao lado de decisões meritórias, há, como no caso da saúde, decisões extravagantes e emocionais, especialmente em matéria de medicamentos e terapias, em que, por total ausência de conhecimento para a

\footnotetext{
${ }^{2}$ Tem-se em conta, por exemplo, os resultados da pesquisa financiada pelo Conselho Nacional de Desenvolvimento Científico e Tecnológico (CNPq) que vem sendo conduzida por Delduque, M.C.; Marques, S.B. no âmbito do Programa de Direito Sanitário da Fiocruz Brasília, o qual analisa as decisões judiciais em saúde em âmbito nacional. Romero (2010), em estudo realizado no Distrito Federal encontrou, também, essa tendência na jurisprudência do Tribunal de Justiça do Distrito Federal e Territórios.
} 
avaliação do impacto, decisões proferidas em processos individuais sobre a realidade do segmento sanitário põem em risco a continuidade das políticas públicas de saúde.

Ao revés, gestores da saúde reclamam da indústria de liminares em que se transformou o Judiciário em matéria de medicamentos, terapias, insumos, tratamentos e produtos de saúde. Ocorre que, como bem lembrado por Dallari (2002, p. 65) "não há indústria sem matéria-prima". Desse modo, existem de fato atos inconstitucionais e ilegais de alguns gestores do SUS a ensejar demandas merecedoras de decisões liminares que garantam aos peticionários seu direito líquido e certo à saúde. Afinal, sendo a saúde um direito fundamental não estariam os juízes autorizados a intervir quando as políticas públicas estivessem em dessintonia com o direito? As políticas públicas não devem estar irremediavelmente subordinadas aos direitos fundamentais?

Como se vê, a judicialização da política de saúde é fenômeno complexo, em relação ao qual não se pode atribuir culpa exclusiva, isto é, não se pode arbitrar exclusivamente a nenhum dos atores sociais que compõem o cenário atual do fenômeno da judicialização das políticas de saúde (gestores públicos, juízes, pacientes, médicos, formuladores de políticas etc.) a culpa pela multiplicação dos casos jurídicos, com notório impacto na economia e na gestão do sistema de saúde.

Em vista disso, o Supremo Tribunal Federal (STF) fez realizar audiência pública sobre políticas públicas de saúde. Os senhores Ministros do STF ouviram cinquenta especialistas, entre magistrados, professores, advogados, defensores públicos, promotores e procuradores de justiça, gestores e usuários do Sistema Único de Saúde, médicos e técnicos de saúde, sobre diversas questões que envolvem a garantia efetiva do Direito à Saúde no Brasil, intimamente relacionadas com as políticas públicas de saúde e a estruturação do Sistema Único de Saúde. ${ }^{3}$

O espaço do diálogo está aberto e as partes envolvidas na judicialização das políticas de saúde estão dispostas à escuta.

Mas não seria verdade que, para as decisões em saúde, desejável seria a constituição de varas especializadas em todos os tribunais do País ou mesmo desejável delinear-se um perfil ideal de juiz-social?

\footnotetext{
${ }^{3}$ A audiência pública da saúde promovida pelo Supremo Tribunal Federal ocorreu nos dias 27, 28 e 29 de abril e 4, 5 e 7 de maio de 2009.
} 
O raciocínio judicial no momento da decisão segue um esquema. $O$ método dedutivo, certamente, é a forma mais simplificada para explicar este momento na tradição da teoria da decisão judicial.

O juiz - bem ao estilo de Sherlock Holmes - resolverá o caso mediante pura dedução, porque existirá sempre uma regra válida (elemento normativo) a ser aplicável ao caso concreto (elemento fático) que ele, obrigatoriamente, deverá observar para seu convencimento e julgamento (elemento dedutivo), sob pena de julgar contra legem.

No método dedutivo, o juiz começa por delimitar o suporte fático do ponto de vista jurídico, isto é, os fatos que estão devidamente comprovados no processo e pelos meios admitidos pelo Direito, porque fatos sem provas válidas não são considerados fatos. Em um segundo momento, o juiz identificará um conjunto de premissas jurídicas válidas, a invocação de uma norma, que qualifique os fatos anteriormente apreciados. Essa identificação é extremamente relevante, pois não se trata de uma mera transcrição de normas, mas da identificação da norma válida seguida da interpretação de seu enunciado, em vista do fato concreto.

Em matéria de decisão no tema da saúde, é preciso que as partes tenham o cuidado de trazer aos autos o máximo de informação normativa possível para que o juiz possa tomar ciência do arcabouço jurídico sanitário. É muito comum ouvir queixas de que os juízes decidem questões sanitárias com base na Constituição e nas leis federais. Ocorre que grande parte da regulação dessas matérias de saúde está formalizada em atos infralegais que, muitas vezes, não chegam aos autos para o conhecimento daquele que vai decidir.

É preciso, igualmente, que a linguagem normativa tenha clareza, vez que a norma que é simples de interpretar permite que as pessoas ajustem a sua conduta a ela de modo simples. Nesse ponto, o arco normativo infralegal da saúde necessita de maior clareza e melhor adequação à boa técnica legislativa, pois, atos normativos que regulam determinadas atividades são de difícil entendimento e interpretação pelo destinatário da norma e por aqueles que deverão aplicar as regras. 
Por fim, o juiz analisa os fatos, sua correspondência com a norma aplicável, dando solução ao caso pela via da dedução.

O juiz representa o Estado e esse impõe que a solução para as divergências nascidas entre os litigantes se faça de maneira correta e rápida, de modo a restabelecer-se a paz social. Assim, o juiz tem a função de dirimir as contendas entre os indivíduos ou entre indivíduos e grupo, ou entre grupos e, nesta atividade jurisdicional, não se deve afastar do objetivo estatal. Para isso, é investido de poderes, assume deveres e responsabilidades inerentes à sua posição no processo judicial.

O julgador, ao decidir, agrega, como componente de sua decisão, "o coeficiente pessoal desde o seu quadro psicobiológico até a dosagem da sua mentalidade política" (Pontes de Miranda, 1997 p. 405), limitado, entretanto, no seu livre convencimento pela lei que o obriga: a) a ter sua convicção condicionada aos fatos nos quais se funda a relação jurídica controvertida; b) às provas desses fatos; c) às regras legais; e d) ao dever de demonstrar em sua decisão as razões do seu convencimento e motivar o porquê da atribuição valorativa com que foram consideradas as provas.

$\mathrm{O}$ ato decisório de um julgador se materializa na sentença. Entende-se que a sentença é a vontade do Estado declarada pelo juiz. A sentença exige fundamentação, quando o juiz deve expor sua motivação e todo o horizonte dentro do qual se desenvolveu, tornando públicos os fundamentos que o levaram a tal decisão. Desse modo, não há julgamento livre. A sentença por simples intuição não prevalece, pois o vínculo ao livre convencimento do juiz obriga-o à motivação da decisão, que passa a ser um dever legal do julgador. Há uma liberdade de convicção que convive com a dependência das provas existentes no processo e com os ditames da lei.

Ocorre que o método funciona bem para os casos fáceis, sendo de pouca valia para os chamados casos difíceis.

Vê-se que o sistema jurídico, com base no seu sistema operacional hermético, constrange o juiz a decidir. Isso só reforça a ideia do juiz como a boca da lei. Mas, de outro lado, o non-liquet garante a abertura do sistema para demandas infinitas, obrigando o Judiciário ao papel de intérprete, criador e 
construtor do direito. Com base nesta regra, "os Tribunais são o centro do sistema jurídico, tudo o mais, inclusive a legislação, representa a periferia" (Luhmann, 1990, p. 160). Essa atividade sentenciadora dos Tribunais e de desenvolvimento do Direito não pode ser antecipada nem produzida nem impedida pelo legislador porque ela resulta da proibição da recusa de Justiça.

Desse modo tem-se, conforme Lorenzetti (2009), três posições: a) todos os casos são fáceis e podem ser resolvidos pelo método dedutivo; b) todos os casos são difíceis - aqueles em que se detecta dificuldade no elemento normativo a ser aplicado ou na prova dos fatos ou na própria dedução e devem ser resolvidos com base nos princípios; e, por fim, c) os casos fáceis devem ser resolvidos pelo método da dedução e os casos difíceis devem ser resolvidos pela argumentação.

Entende o autor que a terceira posição é a mais aceitável, já que não ignora que "a maioria dos casos é dedutivamente resolvida (casos fáceis), e com exceção existem dificuldades normativas ou fáticas, que se resolvem com base na argumentação jurídica (casos difíceis)" (Lorenzetti, 2009, p.159).

O sistema de normas fundamentais é totalmente aberto sugerindo interpretação. Os casos difíceis, quando chegam ao Poder Judiciário, são resolvidos a partir da interpretação, o que envolve, evidentemente, discricionariedade.

Hart (1977) aborda em seu texto a submissão à lei versus a inventividade judiciária e o limite que se pode dar quando há indeterminação da regra e estáse diante de um caso difícil. O pesadelo de Hart é a politização do Judiciário, um juiz sem amparo da escolha democrática assumindo um papel legislativo. A regra é de tal indeterminação que faz com que o julgador faça uma nova regra. Mas ele deve procurar a lei e não fazer a lei. Para além do pesadelo, Hart defende o nobre sonho, em que afirma haver sempre uma solução legislativa para qualquer situação fática, mesmo nos casos difíceis.

O fato é que toda regra é uma generalização construída a partir de vários casos individuais de onde se tira um paradigma - a generalização é feita de algo comum advinda do diverso, o que constitui sua indeterminação. Esta a virtude da regra. Nenhum de nós é capaz de determinar casos futuros: as regras formuladas pelos legisladores (homens comuns) são sempre baseadas em casos 
passados. Por outro lado, o vício da regra é que ela continua particular, ou seja, mesmo que ela seja capaz de ser geral e prever casos futuros, ela é particular.

Quando surge um caso que não se resolve a partir da generalidade da regra baseada em casos individuais passados, este é o caso difícil, é quando aparece o juiz que cria a regra, o que legisla. A frente de casos difíceis, o juiz parte do pressuposto de que está diante de extremos - que são sempre viciosos - e é preciso encontrar o meio termo. O juiz deve se guiar pelos princípios e aplicar o juízo de ponderação (Lorenzetti, 2009).

No tema da saúde, os casos jurídicos postos à decisão judicial enfrentam uma magistratura não preparada para decidir sobre este novo direito - o Direito Sanitário 4 . Falta-Ihe conhecimento dos fundamentos teóricos da matéria e do arcabouço doutrinário deste novo ramo do direito. Esse fato agregado ao arco normativo infralegal da saúde disperso em inúmeras portarias e resoluções, muitas delas com redação inadequada e inobservância da boa técnica legislativa, adiciona uma dificuldade a mais para uma decisão conveniente para o setor da saúde.

É preciso estar atento às questões políticas que chegam ao Judiciário, há de se ter mecanismos de proteção da comunidade para esse papel político dos juízes não eleitos. Mas, por outro lado, há o vício oposto, o de alijamento desse Poder da responsabilidade que tem. E uma vez mais se socorre de Capelletti (1999, p. 60), para registrar que, para as decisões em saúde, é desejável um "Big Judiciary" capaz de ser um guardião adequado e contrapeso eficaz dos ramos políticos.

A Revista da Escola Nacional da Magistratura da França, em sua edição de junho de 1990, descreveu que, para a profissão de magistrado, "não existe de maneira evidente nenhum outro modelo de referência, nenhuma outra definição unívoca de uma profissão que tende a envolver-se de forma tão multiforme e pluralista" (Ost, 1993).

Guarnieri (apud Campilongo, 2002) aponta, com base em parâmetros de autonomia política e criatividade jurisprudencial, quatro tipos de juiz: o juiz-executor; o juiz-delegado; o juiz-guardião e o juiz-político.

\footnotetext{
${ }^{4}$ Entende-se por Direito Sanitário o ramo do direito formado pelo conjunto de modelos científicos, conceitos teóricos e normas jurídicas capazes de compreender e concretização o direito humano fundamental à saúde.
} 
O juiz-executor tem como maior característica a baixa autonomia e a baixa criatividade. Julga de forma dedutiva e linear. É um juiz forjado na lógica construída no Século XIX que tem sua racionalidade intimamente relacionada com as codificações e o privilégio da definição do sentido do direito centrada unicamente no legislador. Este juiz não tem espaço para a atuação criativa, pois tem grande passividade perante a lei. Aproxima-se da escola da jurisprudência dos conceitos.

Um segundo modelo de juiz, para Guarnieri, é o juiz-delegado. Sua independência é baixa, mas sua criatividade é alta. Esta criatividade é colocada à disposição de quem delega poderes, embora não seja uma carta branca. Este juiz age como se um legislador fosse, faz suas escolhas em vista do interesse coletivo e sua atividade criativa deve ser vista como um socorro aos outros poderes e um mínimo de previsibilidade jurídica é requerido, não se tolerando soluções totalmente inconsistentes com o ordenamento. (Campilongo, 2002).

O terceiro modelo é o do juiz-guardião. Muito assemelhado ao que se encontra no realismo americano, ou jurisprudência sociológica. Esse juiz tem o limite de sua atuação na Constituição, o que exige uma baixa criatividade. "O juiz-guardião deve opor-se à comunidade e aos demais Poderes sempre que estes ameacem a Constituição" (Campilongo, 2002, p. 53).

Por fim, o juiz-político. Combina alta autonomia política com alta criatividade, o que não significa total liberdade, porque sempre haverá textos a interpretar e hierarquias a observar. Esse modelo, encontrado principalmente nos Estados Unidos, lança o juiz em um contexto onde outros atores desempenham papéis políticos equivalentes e o excesso de liberdade do juiz limita a demarcação do direito/não direito, podendo ocasionar a corrupção do sistema jurídico.

François Ost (1993) também se debruçou sobre o tema do perfil ideal de juiz, distinguindo três modelos: o Juiz Júpiter, o Juiz Hércules e o Juiz Hermes.

O juiz jupiteriano guarda semelhança com o juiz-executor de Guarnieri, aquele que aplica a norma ao fato. Forjado no direito liberal, entende que o juiz não deve fazer política e muito menos contrapor-se aos ditames da norma, que deve ser aplicada ao caso concreto pela racionalidade lógico-dedutiva. 
O juiz Hércules assemelha-se aos juízes delegado e guardião de Guarnieri. Hércules extrai a regra do fato, isto é, desloca do legislador para o magistrado o privilégio do sentido do direito, a decisão carrega o método da racionalidade indutiva do fato à norma. Ost usa a figura de um funil, para simbolizar o trabalho do juiz Hércules, que carrega o mundo nas costas. É um engenheiro social, um juiz forjado no direito social.

Por fim o juiz Hermes, que faz par com o juiz-político. "Ocupa-se de um direito sem vértice nem centro, sem pico nem canalização direcionada e produto de uma constante circulação de discursos" (Campilongo, 2002, p. 57). Resultam disso altas taxas de independência e criatividade, gerando enorme politização da magistratura.

Embora Ost afirme que o juiz Júpiter e o juiz Hércules não atendem às expectativas da pós-modernidade, á certo que:

"además del hecho de que uno y otro han entrado hoy en crisis, ellos solo ofrecen representaciones empobrecidas de la situación que pretendían describir en su época. La sociedad y el Derecho postmoderno merecen algo mejor que este artificio teórico"s (Ost, 1993, p. 171).

Reconhece-se que o atual estágio de desenvolvimento do Direito Sanitário e das questões levadas ao Poder Judiciário em matéria de saúde no Brasil devem ser julgadas por um juiz de modelo Hércules, ou seja, uma mescla dos modelos juizguardião e juiz-delegado de Guarnieri (apud Campilongo, 2002), um juizepidemiologista, focado na lógica social do sistema de saúde, detentor de conhecimentos sobre orçamento público e financiamento da saúde, um magistrado que vai além da norma, mas no equilíbrio entre a necessidade real dos indivíduos e a capacidade do sistema.

Ainda está longe a apreensão das questões sanitárias pelos membros da magistratura brasileira, o que poderia lhes garantir decisões políticas baseadas em lógicas que não suprimissem a função precípua do sistema sanitário que é a de garantir por intermédio de políticas públicas sociais e econômicas ações e serviços de saúde com o escopo de atingir indicadores de saúde ideais para toda a população brasileira, concretizando-se o direito à saúde.

\footnotetext{
5 "Apesar do fato de que um e outro [juízes Júpiter e Hércules] tenham entrado em crise, eles oferecem apenas representações empobrecidas da situação que pretendiam descrever em sua época. A sociedade e o Direito pós-modernos merecem algo melhor do que esse artifício teórico". Tradução livre da autora.
} 
A formulação de políticas públicas e o enfrentamento dos problemas de saúde em geral ainda são incógnitas para a magistratura nacional que não possui, por enquanto, conhecimento acumulado para proferir decisões que possam corrigir e influenciar as policies sanitárias de modo lógico e estruturado.

O Direito, enquanto área do conhecimento, ainda não se apropriou do Direito Sanitário como fonte de seus estudos. Ainda é comum se ver, em faculdades de Direito, a alusão ao Direito Administrativo como o ramo do Direito em que se assenta o Direito Sanitário. Nega-se sua autonomia científica e isso tem reflexo direto na formação acadêmica dos futuros juízes e operadores do direito em geral ${ }^{6}$. O Direito, enquanto ciência, tem grande dificuldade de se abrir para a interdisciplinariedade, reproduzindo-se no interior das faculdades uma lógica que remonta o Século XVIII, enquanto o Direito Sanitário, como a maioria dos direitos sociais, é um direito do Século XXI (Dallari, 2007).

\footnotetext{
${ }^{6}$ Necessário ressaltar uma das passagens mais brilhantes da obra de Aith (2007) e que põe fim a uma longa discussão doutrinária: a construção dos fundamentos afirmativos do Direito Sanitário, como ciência autônoma. O autor considera o Direito como a tradução normativa da vontade popular e apresenta o sistema normativo da saúde como ciência, mostrando a conexão direta com o contexto social ao qual pertence. Com isso, faz lembrar o marco fundamental do direito à saúde estabelecido em 1988 pela sociedade brasileira e finaliza sua linha de pensamento afirmando que o Direito Sanitário não pode ser compreendido apenas como um simples composto de legislação e jurisprudência, mas como uma ciência que reúne em si a vontade coletiva da sociedade.O autor ainda acrescenta a esta conceituação, a característica transversal difusa do Direito Sanitário e mostra que, para além de seu próprio domínio normativo, o Direito Sanitário reúne, na sua complexidade, aspectos relacionados com outros ramos do Direito, aspectos esses que, direta ou indiretamente, relacionam-se com a saúde e dialogam permanentemente, com a Medicina, a Sociologia, a Administração Pública, a Filosofia e outros. Também Dallari (2007), em que reivindica o Direito Sanitário como campo do saber e ramo autônomo do Direito.
} 


\section{Referências bibliográficas}

AITH, Fernando Mussa A. Curso de Direito Sanitário. São Paulo: Quartier Latin, 2007. 406 p. ISBN 85-7674-262-4.

AMARAL, Gustavo. Direito, Escassez e Escolha. Rio de Janeiro: Renovar, 2001, 256 p. ISBN 85-71-47281-5.

APPIO, Eduardo. Controle Judicial das Políticas Públicas no Brasil. Porto Alegre: Juruá, 2007, 302 p. ISBN 85-36-20877-5.

BARROSO, Luís Eduardo. Judicialização, ativismo judicial e legitimidade democrática. Revista Eletrônica de Direito do Estado. n. 18, abr./maio/jun. 2009 Disponível em: http://www.direitodoestado.com/revista/REDE-18-ABRIL-2009LUIS\%20BARROSO.pdf Acesso em: 11 jul 1012.

CAMPILONGO, Celso F. O direito na sociedade complexa. São Paulo: Max Limonad, 2000. ISBN 85-02-08125-X.

Política, Sistema Jurídico e Decisão Judicial. São Paulo: Max Limonad, 2002, 193 p. ISBN 85-7549-002-8.

CAPPELLETTI, Mauro. Juízes Legisladores? Porto Alegre: Sergio Antonio Fabris. 1999, 69 p. ISBN 85-88-27828-6.

DALLARI, Dalmo de A. O poder dos juízes. São Paulo: Saraiva, 2002, 166p. ISBN 8502-03923-7.

DALLARI, Sueli G. Balanço da saúde no Brasil: SUS, participação social, formação sanitária e agências reguladoras. Brasília: Jornal SindjusDF, maio 2007, p. 12 e 13.

HART, Herbert H. American Jurisprudence through English eyes: the nightmare and the noble dream. 1977. Disponível em:

http://digitalcommons.law.uga.edu/lectures_pre_arch_lectures_sibley/33/. Acesso em $1^{\circ}$ ago 2012

LOEWENSTEIN, Karl. Teoria de la Constitución. Alfredo Gallego Anabitarte (trad). Barcelona: Ariel, 1970.

LORENZETTI, Ricardo Luis. Teoria da Decisão Judicial. Fundamentos de Direito. Bruno Miragem (trad). São Paulo: Revista dos Tribunais, 2009, 395 p. ISBN 85-2033509-3

LUHMANN, Niklas. A posição dos Tribunais no Sistema Jurídico. Peter Naumann (trad). Revista Ajuris, 49:150-167, 1990. ISSN 1679-1363.

. Law as a Social System. Klaus A. Ziegert (trad). Oxford: Social-Legal Studies. 2004, 460 p. ISBN 01-98-26238-8.

OST, François. Júpiter, Hércules, Hermes: tres modelos de juez. Revista Doxa Cuadernos de Filosofia del Derecho. 14, 1993. Disponível em: < http://www.cervantesvirtual.com/servlet/SirveObras/01360629872570728587891/cuad erno14/doxa14 11.pdf. >Acesso em 17 julho 2012

PONTES DE MIRANDA, Francisco C. Comentários ao Código de Processo Civil. Tomo I, art. 1 $^{\circ}$ 45. Rio de Janeiro: Forense, 1997. 
ROMERO, Luiz Carlos P. A jurisprudência do Tribunal de Justiça do Distrito Federal em ações de medicamentos. Revista de Direito Sanitário, 11(2):11-59, 2010. ISSN 1516417-9.

VILLAS BÔAS F', Orlando. O direito na teoria dos sistemas de Niklas Luhmann. São Paulo: Max Limonad, 2006, 268 p. ISBN 85-75-49022-2. 